
\title{
R Reserach S Suare \\ Experiences of Seeking Antenatal Care and Delivery Among Teenagers at Health Facilities in Kibuku District, Eastern Uganda
}

Robert K Basaza ( $\square$ rbasaza@gmail.com )

Uganda Christian University

Josephine N Mawerere

Uganda Christian University

Rebecca Namusana

Uganda Christian University

\section{Research}

Keywords: Experiences, Antenatal care, delivery, teenage pregnancy, Uganda

Posted Date: September 3rd, 2020

DOI: https://doi.org/10.21203/rs.3.rs-70097/v1

License: (c) (i) This work is licensed under a Creative Commons Attribution 4.0 International License.

Read Full License 


\section{Abstract}

Background: Uganda is ranked $14^{\text {th }}$ out of 54 countries in Africa with the highest levels of teenage pregnancies. The teenage pregnancy rate in Kibuku District in 2016 was at 35.8\%, higher than the average rate in Uganda (25\%) and also above the average one for rural areas in Uganda which was at $27 \%$. Unfortunately, there is limited information on the experiences of seeking antenatal care and delivery among teenagers in the district.

Method: This paper explored what these teenagers experience when they seek services at health facilities in Kibuku district, Eastern Uganda. This study used a phenomenological design. Data was collected using in-depth interviews from pregnant teenagers aged 13-19 years, seeking antenatal care (ANC) or who had delivered. They were purposively selected to participate in the study. Data collected was thematically analyzed through coding.

Results: Most teenage mothers know the importance of seeking ANC and delivering from a health facility. Unfortunately, only a few seek services early due to some experiences. These include personal experiences like financial constraints; interpersonal experiences like support they receive from the people they stay with who include husbands and parents, medication given, health workers' attitude and health education given.

Conclusion: The personal experiences of pregnant teenagers or those who had delivered at health facilities is that they knew the importance of seeking ANC and delivery at health facilities. The experiences with the health facilities also contributed to the seeking behavior of the teenage girls. For example, the comfort received by the girls at the facility, medication administered, the way they were treated by the health workers and the availability of utilities. The teenage girls need to be sensitized by health and social workers about the sensitive nature of their health when they are pregnant so that they are able to make personal decisions.

\section{Plain English Summary}

Background: Uganda is ranked $14^{\text {th }}$ out of 54 countries in Africa with the highest levels of teenage pregnancies. The teenage pregnancy rate in Kibuku District in 2016 was at 36\%, higher than the average rate in Uganda (25\%). Unfortunately, there is limited information on the experiences of seeking antenatal care and delivery among teenagers in the district.

Method: This paper explored what these teenagers experience when they seek services at health facilities in Kibuku district, Eastern Uganda. This study used a qualitative research that focuses on the commonality of a lived experience within a particular group so as to construct the experiences. Data was collected using in-depth interviews from pregnant teenagers aged 13-19 years, seeking antenatal care (ANC) or who had delivered. They were purposively selected to participate in the study. 
Results: Most teenage mothers know the importance of seeking ANC and delivering from a health facility. Unfortunately, only a few seek services early due to some experiences. These include personal experiences like financial constraints; interpersonal experiences like support they receive from the people they stay with who include husbands and parents, medication given, health workers' attitude and health education given.

Conclusion: The personal experiences of pregnant teenagers or those who had delivered at health facilities is that they knew the importance of seeking ANC and delivery at health facilities. The experiences with the health facilities also contributed to the seeking behavior of the teenage girls.

\section{Background}

Teenage pregnancy occurs to a girl aged 13-19 years [1] and continues to be a public health concern globally. According to WHO [2], an estimate of 21 million girls aged 15-19 and 2 million girls under 15 years become pregnant in developing countries annually. Additionally, approximately 16 million girls between 15-19 years and 2.5 million girls under 16 years give birth each year in developing countries. Of note worthy, other than any other continents, of the 20 countries in the world having the highest teenage pregnancy rates, 18 countries come from Africa [3].

In Uganda, teenage pregnancy and child bearing have been noted as major social and health concerns for some time and she was ranked 14th out of 54 countries in Africa with the highest levels of teenage pregnancies [4]. Currently, the average prevalence of teenage pregnancy in Uganda is as high as $25 \%$ with $19 \%$ having had a live birth and $5 \%$ pregnant with their first child. Close to a third $(27 \%)$ of these teenage pregnancies are occurring in rural areas and almost a fifth (19\%) in urban areas [5]. The Eastern and East Central regions showed the highest rates of teenage pregnancy in Uganda with $30 \%$ and $32 \%$ respectively [6].

The teenage pregnancy in Kibuku District in 2016 was at 35.8\%, high above the average rate in Uganda $(25 \%)$ and also above the average for rural areas in Uganda which was at $27 \%$ [5]. The findings suggested that teenagers generally lacked knowledge about sexual and reproductive health. This was mainly due to inadequate sex and reproductive health education, poor parent-teenager communication as most of the teenagers found it difficult to discuss sex and reproductive health matters with their parents. Despite the overwhelming number of teenage pregnancies, very few of the teenagers sought antenatal care services and delivered from health facilities. This could be attributed to many experiences they encountered which kept them away as a result of their position in society [7].

In Kibuku district, a total of 11,025 mothers attended ANC first visits in the 16 health facilities in 2017. Of which, 2,275 (25\%) were teenagers aged 10-19 years. Similarly, a total of 6,487 (61.0\% of the expected deliveries) was institutional delivery and among those who delivered at the health facilities, 1643 (25\%) were teenagers [8]. Unfortunately, there is limited information 
on the experiences of seeking antenatal care and delivery among teenagers in the district. A study by Manzi in Kibuku for example focused on 'Factors associated with teenage pregnancies and its effects in Kibuku Town Council, Kibuku District' and did not cover the entire district [9].

\section{Methods}

\section{Study design}

This paper explored what these teenagers experience when they seek services at health facilities. This included personal, interpersonal and health facilities related experiences of seeking antenatal care and delivery at health facilities in Kibuku district, Eastern Uganda. This study adopted a phenomenological design. It focused on describing what all participants had in common as they experienced a phenomenon. The design allowed the research team to explore and develop an in-depth understanding of the experiences of seeking antenatal care and delivery among pregnant teenagers or those who had delivered in the health facilities in the district. It also enabled the research team to unveil details about the experiences of pregnant teenagers or those who had delivered within the antenatal facility environment.

\section{Study area and setting}

The study was conducted in Kibuku district, located in Eastern Uganda, and one of those noted for high teenage pregnancy rates in Uganda and with low ANC seeking and delivery in health facilities. The district has a total population of 202,033 with 27,373 being females aged between $10-19$ years of age [10]. The district has 16 health units of different categories by ownership: 4 Government Health Centre II (subdispensaries), 7 health centre III (dispensary) and 1 health centre (IV). It also has 4 private owned small clinics. All the health units are evenly distributed around the district but lack the basic equipment to offer reasonable services and require rehabilitation and equipping. This study was conducted at five health facilities that were randomly sampled.

\section{Study population}

The respondents were teenagers aged 14 to 19 years and were pregnant or had delivered from any of the sampled health facilities. This population was targeted because it is teenagers who are more disadvantaged in healthcare seeking and would therefore be in better position to put forward their experiences of seeking ANC and delivery in the facility.

\section{Sample size}

The sample size of the population was twenty-seven teenagers who were pregnant or had delivered from a health facility. However, this was guided by a criterion of saturation. The criterion was used in such a way that one adolescent mother was interviewed followed by another, until redundancy was achieved. The teenagers were interviewed until the experiences they were reporting added nothing new to the information already captured in the previous interviews held with other mothers.

\section{Sampling procedure}


Kibuku district was the study location, purposively sampled because it is one of the districts in Eastern Uganda with high levels of teenage pregnancies and low antenatal care seeking behavior yet not much is known to justify the low behavior. In the district, the study was carried out at the health facilities as opposed to the community because it was easier to access pregnant teenagers seeking antenatal care or those who had delivered. This was made easy by finding out days when the sampled facilities offered antenatal care or by identifying those who had delivered in the facility. These were screened to find out if they met the inclusion criteria. Healthcare providers were consulted to help in identifying any other teenagers who sought antenatal care or delivery and when a case was identified, she was taken through the informed consent process and requested to participate.

\section{Eligibility criteria}

\section{Inclusion}

The teenagers residing within the given area of study that were pregnant and seeking antenatal care or had delivered in any of the selected facilities in the district and had consented to take part in the study.

\section{Exclusion}

Teenagers who did not consent to take part in the study.

\section{Data collection}

In-depth interviews were used as the main data collection method. This method provided a situation where the participants' descriptions could be explored, probed and elaborated. An interview guide was developed to aid this (provided as a supplementary file). A quiet and private room was used for interviews and data was collected once from each participant using the interview guide. The interviews helped in gathering views pregnant adolescents had regarding the antenatal and delivery services they received. Each interview took approximately 30 to 45 minutes and was conducted in Lugwere, the local language commonly used in the community. English was used with a few participants who could express themselves well in this foreign language. In addition, the Research Team probed for more information throughout the interview period to allow each participant to share her personal perspectives and avoid 'contaminating the data'. The interviews were audio-taped with permission from the participants and field notes taken to incorporate contextual experiences that could add meaning to the research findings. Data saturation was reached after twenty-seven participants had been interviewed.

\section{Data management}

Field notes were written to document reflections on a given session. Necessary information was also recorded with permission from participants, using a digital recorder. The raw data from one interview was transcribed from audio records before conducting another to verify the accuracy of the information. The information generated was then typed and saved in a computer following objective thematic areas generated in the research. All transcripts were checked against the recordings. Notes taken by the research team during interviews including non-verbal communications that emerged were included in the 
data to enrich the information. Hard copies of documents and equipment were kept in a file folder in a secure place.

\section{Data analysis}

The data was analyzed, using the thematic analysis approach. Themes were created from the codes by grouping together similar codes that emerged from the data. To facilitate the analysis, the interviews were first transcribed verbatim by checking the transcripts against the audio recordings for accuracy. The field notes were added to the interview transcripts to provide a complete dataset for analysis. This allowed themes to be modified as the data analysis process unfolded. The combined transcript (interviews and field notes) were read several times to identify meaningful units of the text.

The research team created initial codes for segments that were of particular interest. Codes were developed from the key words in the transcript to ensure that the participants' voices were accurately captured to preserve the richness of the data, and the context of the interviews. The team also sorted out codes which were valuable for addressing the research questions into categories reflecting dominant themes within the data set. From the initial codes, the team proceeded to create themes from the initial codes. The team read through the themes multiple times to ensure that it was an accurate reflection of the data. Common themes were grouped together to create thematic networks. These thematic networks meant that themes were linked together under a main theme or heading. The data was then interpreted to describe the emerging findings. The themes were developed inductively in order to stay close to the data. During the data analysis, the research team kept cross-checking the themes with the transcripts and analytical notes to ensure that they were coherent and consistent with the data to maximize their reliability.

\section{Quality control}

To ensure quality of information obtained, various measures were taken to ensure trustworthiness. These measures included credibility, transferability, dependability, reflexivity and confirmability. In this study, trustworthiness of the information obtained was important for effective communication of the research findings:

\section{Credibility}

The purpose of the study was explained to the participants and their cooperation sought. As such, credibility was more of personal and interpersonal than methodological. Participants were seen as individuals in their own right, and their uniqueness was respected to facilitate revelation of information. The research team tried to establish a position of trust by being honest. Likewise, a climate of freedom was created so that participants could freely express their feelings and opinions without fear.

\section{Transferability}

The possibility that the findings will be found in one context by a given qualitative study would be applicable to another context was confirmed by sampling teenagers who were pregnant and seeking 
antenatal care or had delivered from various randomly selected health facilities in the district in order to increase generalizability and thus ensure transferability.

\section{Dependability}

Pre-testing of research tools and instruments was done prior the study to make sure they were valid and reliable. Four persons of a similar sample but who did not participate in the actual study were used for this particular purpose in one of the health facilities from a neighboring district. The pre-test subjects were encouraged to make comments and suggestions concerning the interview guide for clarity of questions and relevance. This was done to ensure that the questions were understood by the respondents and that there were no problems with the wording. This helped to rectify the inadequacies in the instruments before they were administered thus assuring credible information. In addition, the research team consistently examined the research process as it occurred, and ensured that all the selected teenagers were probed using the same questions and guided in the same way through all the interviews to ensure dependability of the information.

\section{Confirmability}

To ensure this, the participants' first-hand experience of what they went through formed the basis of the study rather than the research team's perceptions or imaginations.

\section{Reflexivity}

The team continuously probed for more information to allow each participant share her personal perspectives and avoid 'contaminating the data'. This made it important to ensure reflexivity so that the research team would not influence the participant into providing information based on his or her own subjective perceptions.

\section{Ethical approval}

The approval was first sought from the University Ethical Review Committee, with approval number, 1311600-0228. The study participants were then duly informed about the purpose of the study and why it was important for them to participate in it. Informed consent was sought from respondents before and no interview was conducted against this ethical principle. The participants were also informed that they had a right to withdraw from the study at any time in case they felt uncomfortable and could not continue. The study ensured that confidentiality was promised to the participants during data collection and was kept up to the reporting of the findings and, all the values of the participants were respected.

\section{Results}

Twenty-seven teenagers in the age bracket of 14 to 19 years participated in the study. The majority $(24 / 27)$ claimed to be married while $3 / 27$ were single. In regard to religion: 9/27 were Catholics, 8 were protestant, 2 Born Again Christians and 8/27 were Moslems. Their levels of education ranged between four years of education to eleven years (Primary four to Senior 4 in Ugandan System) with the majority 
$(20 / 27)$ having not gone beyond their primary levels of education. The majority were unemployed (14/27), whereas over a third were farmers (11/27), one was a shop keeper and another, a housewife. The majority were carrying their first pregnancies $(21 / 27)$, three carrying their second pregnancies and three having their first child. These teenagers were receiving antenatal care or had delivered from any of the sampled health facilities at the time of the interviews. True identities of the participants were coded using initials of the health facilities they sought services from and the numbers indicated their age. Original experiences gathered from the girls were directly quoted to enhance the description of experiences and findings of the study. Results were organized into themes and sub-themes.

\section{Themes and sub-themes}

The predetermined and emergent or sub-themes of the study are presented in Table 1 . The themes emerged from the findings and a number of sub-themes were developed. The predetermined themes were three: personal, interpersonal and health facility related experiences. Each of these had emergent or subthemes.

\section{Table 1 Predetermined and emergent themes}

\begin{tabular}{|c|c|}
\hline $\begin{array}{l}\text { Predetermined } \\
\text { theme }\end{array}$ & Emergent themes and sub-themes \\
\hline \multirow{3}{*}{$\begin{array}{l}\text { Personal } \\
\text { experiences }\end{array}$} & - Timing and decision to go for ANC \\
\hline & - Importance of ANC \\
\hline & Motivation to come for ANC \\
\hline \multirow[t]{2}{*}{$\begin{array}{l}\text { Interpersonal } \\
\text { experiences }\end{array}$} & $\begin{array}{l}\text { Support from spouses, friends and family; Facilitation in form of buying the } \\
\text { necessities, money for transport and feeding, accompanying them and offering } \\
\text { some education. }\end{array}$ \\
\hline & - Decision making power \\
\hline \multirow{7}{*}{$\begin{array}{l}\text { Health facility } \\
\text { related } \\
\text { experiences }\end{array}$} & - Comfort at the facility \\
\hline & - Treatment given \\
\hline & Health worker attitude \\
\hline & Education offered \\
\hline & - Availability and accessibility of utilities \\
\hline & $\begin{array}{l}\text { - Challenges faced (accessibility; distance and affordability, working hours, fear and } \\
\text { stigma) }\end{array}$ \\
\hline & - Health facility compared to services by a traditional birth attendant (TBA) \\
\hline
\end{tabular}


Some of the girls had attended ANC for at least three times, while others were just reporting for the first time. However, many of the girls initiated their ANC visits later than expected. Many of them came when their pregnancies were more than five months. Some were five, others six as well as seven months. Only a few of the girls reported before the five months.

"I have never come here before. The first time I came, I was sent away. I came in September last year and was sent away because I didn't come with my husband so I just moved back home" (KU, 16 years).

"I always come for ANC. I first came when the pregnancy was 6 months because I had fear. For the second, it is 8 months and I started coming at 6 months also. My husband is at times not around. He is the one who delays me. We are told to always come with our husbands when coming for tests" (KD, 19 years).

Some of the girls had been dumped by their husbands either at home or with their relatives and showed no signs of returning.

"This is my first time to come for ANC and it is 7 months. What delayed me is that I was waiting for my husband hoping that he would come back but he did not. He is in Kampala where he works as a porter" (KR, 19 years).

"I have just returned today. I was asked to return on $9^{\text {th }}$ January. I first came when it was 7 months. They used to say that you come with a husband when you are pregnant. The man had left me at the brother's home and there was no kind of support he was offering so I decided to go back home. For me, I am home now but I don't know where he is and what is happening to him. So when I returned to my parents' home is when I started coming here" (KD, 18 years).

Lack of money to procure the necessities required for ANC was also one of the reasons noted for delay to come to the facility.

"This is my first time to come for ANC and its 4 months (smiling). My husband delayed me from coming. He tells that there is no money to buy the polythene bag that we use whenever we go for ANC or in preparation for delivery and other things" (KR, 18 years),

"I have just started ANC today and the pregnancy is 5 months. I delayed to come because the facilitation I have is also little. I didn't have the money to buy a polythene and yet they want it. So for today I got some money to buy it then I came. My husband himself is in Entebbe (over $100 \mathrm{Km}$ from home) and that is where he works and that is their home. He doesn't send any assistance even when I call they don't pick me up, I don't know what the problem is" (KR, 19 years).

One of the participants just decided that she wanted the baby to first develop before she could come to the facility. 
"Yes, I have come for ANC before. This is the third time. I first came when the pregnancy was 5 Months old and is now 7. Nothing prevented me from coming. I decided personally that let this pregnancy first grow then I will go" (BS, 17 years).

\section{Importance of ANC}

Many of the mothers were aware of the importance of ANC to their health and that of their babies. They said that when they come for ANC, they are checked to find out the condition of the baby in the womb, they are also given medicines that help the baby. This was brought out by a number of girls.

"Yes, it is good to come for ANC. You can be able to tell how the baby is, may be you can get enough care, and be able to tell whether the baby is ok in the womb or not" (TR, 17 years).

This was also retorted by others respondents:

"It is good to come for ANC because they examine me and see what illness is in the womb. In case there is any, they give you treatment, they give you medicines and for me that is the good thing I see in it" (KB, 19 years).

"I think that ANC is to get help and I think it is good to come because if there is a problem they can help you" (KB, 19 years).

"Hmm. It is good to come for ANC. Why it is good is that at times it may have an illness and the second reason, they have to see how the child is developing in the womb and the third thing they have to see whether the child is alive in the womb or it has some deformity. That is what brings us for ANC" (KD, 18 years).

"It is good to come for ANC. It is good so that you can know whether what is in the womb is ok; it is alive or dead, it is in the right position or not so that the HW knows and you also know" (KN, 17 years).

\section{Motivation to come for ANC}

Many of the girls were motivated to come for ANC because they felt that was the best opportunity for them to know the condition in which their babies were. A few were motivated after they had got what the $\mathrm{HWs}$ required them to always come along with to the health facility.

"What motivated me to come today is because my husband bought some requirements though he has not bought all but I am hoping that he will buy the rest" (KO, 18 years).

"For the first pregnancy the money was there, we got it fast and we bought the requirements. For this one, I have come now because I got the requirements" (BS, 19 years).

Some of them came because they were feeling unwell and wanted the health workers to help them.

"I came today because I was feeling some pain so I decided to come" (KR, 19 years). 
"I myself saw my lifestyle and another thing at the beginning first of all, when the pregnancy was still young, about 4 months, I experienced some pain as if I wanted to get an abortion but that was before I came so I decided on my own that I should come to the Health Facility" (KT, 17 years).

One of them was also not staying at their home but when she got back home, she started attending ANC.

"What encouraged me to come is the fact that I came back home then I started coming for ANC" (KD, 18 years).

However, one of the participants had a personal drive that pushed her to come:

"What encouraged me to come? I just wanted to come" (KD, 18 years).

\section{Interpersonal experiences}

\section{Support from spouses, family and friends}

Many of the girls felt supported by their families including their husbands, parents, grandparents and even friends. They reported being supported in various ways like being given money for transport, feeding; others would accompany the girls to the facility, some offered guidance in relation to ANC and visiting the Health facility.

"The people I stay with encourage me to come and see that I do not get other diseases like tetanus. They also give me some transport. They educate me as well" (TR, 18 years).

"I stay with mummy, daddy and my husband himself. They give me transport, at times, they accompany me; they come and wait for me and thereafter receiving care, we go back. My husband accompanied me and the mother also accompanied me. They also teach me that going to the health facility is good so that we know what is in the womb" (KN 17 years).

"I stay with my granny and my husband. They bought for me some requirements. My husband bought them. They also tell me the goodness of ANC. They tell me that it is good and you go to the health facility and the HWs see the condition in which you are because there might be things or medicines that are required that you can keep using" (BS, 18 years).

"I stay with my in-laws at home. These people just educate me. They encourage me to come to the Health Facility because you never know I can get a problem and fail to deliver well. Hmm. That is why you see they encourage me that my dear you take care of yourself and go" (KD, 18 years).

"I stay with my husband and his parents. They all decide for me to come for ANC. They educate me, they give me transport and even accompanying me. Hmm...(Thinking) Most importantly is that they educate me on hygiene and my husband is the one who in most cases accompanies me for ANC" (KB, 19 years). 
Some of the girls also offered some piece of advice to their fellow friends. This was obtained in an interaction with one of the girls:

"My friends say me to go for ANC and get to know how the child is growing and every pregnant mother goes for ANC. It helps to know how the child is growing and they ask me how I am feeling (TR, 18 years).

Despite the majority of the participants being supported by the people they stay with, some did not really get that kind of support. Whatever they therefore did was as a result of their personal drive, including the decision making. This was noted in an interaction with one of the participants:

"I stay with my mother-in-law and brothers-in-law. I told them that I was coming to hospital. I just came with my husband so those that I stay with have not in any way helped me as far as ANC is concerned" (KR, 19 years).

\section{Decision making power}

For the majority of the girls, they did not have the decision making power. Most of the decisions to come for ANC were either made by their husbands because they claimed it is their husbands who control them and for some, because they are the heads of the families.

"My husband decides for me on whether to come for ANC because he is the head of the family" (KM, 18 years).

"My husband is the one who decides for me to come for ANC because at times I can forget the date then he reminds me. I have to ask from him" (KD, 18 years).

For others, the decisions were made by the people they stayed with like their parents and grandparents.

"Now the fact that I am staying at home, I first have to request daddy that I am going to the health facility then he allows me. Indeed, he could not refuse because it is mandatory that I have to come" (KR, 19 years).

"Mummy decides for me because she's the one controlling me or taking care of me" (TR, 18 years).

"Mummy decided for me to come for ANC today because I had fear to come because if I come without a husband, am not attended to. You are sent back home" (KZ, 18 years).

Only a few made personal decisions to come for ANC as seen in some interactions.

"I decide for myself to come for ANC. No one at home tells me to come for ANC. I am always encouraged to come to be checked. I don't feel well when I don't come for ANC" (TR, 14 years).

"I decided to come by myself for ANC today. I said that let me go to the chairman and go to the health facility. When I went to him, he wrote for me a letter and I came before they accepted to attend to $\mathrm{me}^{\prime \prime}$ ( $\mathrm{KX}$, 19 years). 


\section{Health facility related experiences}

\section{Comfort of using a health facility}

Many of the girls said that they felt comfortable when they came to the health facility. This is because they felt they had come to the right place and would therefore receive what they have always anticipated; treatment and go back home better.

"I feel comfortable at the health facility because I come and they palpate me and give me some tablets to go and take" (TR, 19 years).

"I feel good when I come to the health facility for ANC because the HWs will have attended to me well and I go back home" (TR, 18 years).

"I have felt some comfort coming here today because I have been tested, given some medicines, palpated and I feel life is not like it has always been" (KV, 18 years).

"I feel comfortable when I come here for ANC. Hmm... I feel comfortable as well when I come to deliver from here. I find my friends and we come" (BS, 19 years).

Some however, since this was their first time were anticipating comfort only after they have interacted with the HWs and received some medication.

"I have not yet felt some comfort. I will feel after I have got some medication" (KR, 19 years).

"I didn't feel comfortable the first time I came because, I was feeling some pain but today I am fine" (KH, 16 years).

\section{Treatment given}

Many of the girls who came were given some kind of medication. Some included vaccination and medicines. Some of them had some slight idea of the importance of the medication they were given. Many of them therefore promised to continue coming to the facilities for the ANC services.

"I was given some iron tablets and some which are two, when you first come; whether they are two or three fansidar tablets? I will be coming back for ANC here" (TR, 17 years).

"I got some medicines when I came here. Some that are for blood when you have delivered, when you over bleed and for some, I was told that I had some flu. I will continue coming for ANC and will even deliver from the health facility because I am still here and still producing" (KB, 18 years).

"I am immunized and given some tablets when I come for ANC and palpation. I hope to come back for the remaining time (laughing), the remaining two times because the months are still there and I think it is good (laughing) because I am not yet relieved" (TR, 18 years). 
However, some of them did not really understand why they had to swallow some of the tablets. Despite the limited knowledge on the importance of the treatment they were receiving, they also promised to continue coming to the facility.

"I was injected and they gave me some medicines. They didn't tell me the importance of the injection. I hope to deliver from the health facility because at times you never know you can get a problem and fail to deliver from the village. I will continue coming here because pregnancy things are difficult" (KD, 18 years).

Unfortunately, some of the girls also said that they had never received any kind of medication from the health facility. This is because whenever they came, they were told that there were no medicines so they got a prescription and were asked to go and get them from physicians.

"They have given me some medicines when I came here. I don't really know how they are called because when I came they just wrote for me on a piece of paper. They just write for me and I go and buy. I hope to continue coming because of the help I am rendered" (KB, 19 years).

"For me for the times I have come, they have not given me any medication but they gave me a mosquito net. I sleep under it and will continue coming for ANC but I don't know why" (KS, 17 years).

\section{Health worker attitude}

For all the girls, on interaction with them, they said that the HWs treated them well. They did not therefore have any problem with the way they were treated by the HWs. They said that the HWs were always calm in the way they talked to them. Even in instances when they failed to do what was expected of them, the HWs were a little hard with them but later attended to them. The HWs were also noted to be patient and kind to the girls.

"There is nothing bad the health Workers can do to us but only give us advice" (TR, 17 years).

The HWs treat the girls well. They do not bark at people, they ask them well (KR, 19 years).

"The HWs treat well. If the ones who come to deliver their polythene bags are far, they assist them with theirs. They give them and they speak with us well" (BS, 17 years).

"The HWs treat us well. They first educate us when we have come with our husbands that you go and tell your husbands to buy for you clothes. They are not rude" (KB, 19 years).

\section{Education offered}

Some girls acknowledged receiving some education when they came for ANC. This they said was important for them as young girls.

"They educate us to come to the health facility with our husbands. But for me I didn't come with mine because I didn't know. They tell us that both of you have to be tested. They also tell us what is required 
when coming for delivery like the polythene and clothes and on diet, we were told that you need to eat some pineapples" (BS, 17 years).

"Like us who are pregnant, they tell us to come with plastic bags, gloves and during delivery you come with everything that is required. That's all I have heard being taught. Even on hygienic, feeding habits" (TR, 14 years).

However, while some claimed the education was adequate, others felt there was some more that they needed to know.

"They educate us like preparing for ANC; clothes, polythene and panties (Hmm.). They also educate us on what to eat like taking millet porridge. We still need to learn more like going for Family planning" (BS, 19 years).

"They teach us that we need to eat well like eating some beans, silver fish, greens. You need to stay in a clean environment. They need to add on what we are taught" (TR, 18 years).

"They have educated us like for a woman when you are pregnant, you need to prepare yourself, you be with a polythene, gloves, petticoats and knickers when you are going to deliver because some people when they come for delivery, they don't even have requirements. Actually like us who are first time mothers, there is a lot that we really need to know because since this is the first time we are getting pregnant, there is a lot that we need to know that we don't know" (KR,19 years).

On the contrary, there are some of the girls who did not receive any kind of education for the times they had visited the health facility. These were captured during interactions with them:

"No, the HWs have never educated us. Even what is required when we are preparing for delivery, they have not yet told us. They have never told us anything so it is about you to know that this is required and what is not" (KF, 17 years).

"For me they have not yet given me any kind of education but I think the education is necessary like when you are pregnant and there is something you can do" (KB, 19 years).

\section{Availability and accessibility of utilities}

Some girls noted that the utilities were enough, but others found that they were not adequate enough and therefore needed to be added. These included the beds, equipment used for checking them, medicines and the limited number of HWs as well.

"They have never given me any medicines; they told me to buy since they were out of stock in the facility. They told me to buy for swallowing but I didn't buy so there's nothing I am swallowing" (KC, 17 years).

"Me if I was to go by what I think, the utilities are not enough. The beds themselves that they use for delivery are few, where the patients themselves rest are few, the medicines, they can tell you to come back 
another day, you come back and they tell you that there are no medicines and you come back another day, then you come back again and in the end, you yourself feel tired and yet it is mandatory that you come" (TR,17 years).

\section{Challenges faced (Accessibility; distance and affordability, working hours, Stigma and fear)}

Many of the girls claimed that the health facilities were accessible and felt the HWs in most cases worked on time save for a few of them who once in a while delayed. However, one outstanding challenge that most girls kept identifying was that the clients were in most cases many and with may be only one HW attending to them.

"At times you come here early but you leave the place late. Only one HW attends to the patients and yet the people are always many. You feel some fear as well but it is now gone. I overcame by involving in conversation with people. For the medicines, they at times tell you to go and buy medicines but they give you some which are there" (BS, 17 years).

"O! at times you come here and sit before the HWs have even arrived like today we came here and found some man complaining that the HWs have delayed to come. I can never get fear to come to the health facility because I decided that I want marriage and what I want is a child" (KT, 18 years).

"...............I don't blame this on HWs but us as individuals as well, we have our lifestyles that are bad like you can be told to come early and you reach at your own time when the HWs are finishing to work and they have also got tired and in their tire, they are also using anger when they don't have any more strength. Sometimes they are also caught up and they delay to reach and at times you come and are told that they won't work and you go back home or you come and you have not come with what they want and you don't have money to buy them. You can be attended to but they also first make you feel the pain because they told you but you did not also think of it" (TR, 17years).

The girls did not also have any stigma apart from a few who were coming for the first time but were later able to get over it.

"The second time I came; they were in for a meeting we were asked us to go back home. But whenever we come they attend to us and they release us early. Transport has never been a problem to me because from where I stay to come here is 500/= and going back is also 500/= only. I only had stigma the first time and that is when my mother-in-law accompanied me because I had fear then. The next time I came back, I came alone and had no fear any more" (KC, 17 years).

"I have got a challenge coming here at times when you lack requirements but we are attended to on time. I at times fear to come here because people will look at me pregnant but it's about staying strong" (KR, 18 years).

Health facility compared to services by TBA 
Many of the girls preferred using the health facility as compared to the TBA. This is because most of them said that at the Health facility, one easily gets immediate attention and assistance.

"I have not yet gone to a TBA and do not really hope to go there. Why? Hmm... Only a few things do they know from what is at a health facility" (BS, 18 years).

"I would prefer to come here because here I find a lot of reference points because a HW can tell you, 'Go and swallow this medicine, go and do this and don't do that because it is going to hurt you but when you go to a TBA, she will continue giving you medicine and you take" (TR, 19 years).

"I will continue coming here to the health facility. Why? (Laughing) There are some TBAs in the village who tell you that your pregnancy is unhealthy and you come here, to the health facility and they tell you that the illness is not there which shows that the TBAs are deceiving" (KB, 19 years).

However, few of the girls said they would go to the TBA only to take medicine, be palpated and depending on the nature of circumstances but would deliver from the health facility due to the nature of assistance offered.

"There are TBAs in the community where I stay and I hope to go there to be palpated. I hope to deliver from the health facility because I can decide to deliver from home and I fail" (KB, 19 years).

"I went to a TBA during delivery, but I had never gone there before but only to deliver. I am sure I can go back" (TR, 17years).

One of the girls felt that the HWs were better confidantes than the TBAs.

"Aaah! I have never thought of going to a TBA. We have one near our home but the ones she helps deliver, she talks about them with others so I would rather come to the health facility" (TR, 14 years).

\section{Discussion}

The findings of the study explored the experiences of seeking ANC and delivery among teenage girls as individuals, with her family and friends and health facilities and therefore gave a picture of what other teenagers could also be experiencing.

\section{Teenagers' personal experiences of seeking ANC and delivery}

Some of the girls delayed seeking ANC and delivery services from health facilities due to absence of the company of their husbands as demanded by health workers yet some just decided that they wanted the pregnancy to first develop before they could go to the health facility. These instances increased chances of pregnancy related complications either during pregnancy or delivery. Respondents were motivated to get to the health facility after they had got the necessities required or when their husbands had returned from wherever they had been. However, some came because they were feeling unwell despite the absence of their husbands whereas some were encouraged to come and check the conditions of their babies in 
the womb. The findings from this indicate that many of the teenage girls were aware of the importance of seeking ANC and delivery services from health facilities. Unfortunately, few of them initiated the ANC visits and delivery services from health facilities and for those who really did, it was in most cases late.

This finding is in line with studies carried out in Masaka and Wakiso districts in Uganda that reported that young girls often found it hard to visit the antenatal clinic due to lack of money to facilitate their movement and necessities that might be required at the health centre [12,14]. This is further related to findings in other studies that showed that teenagers are less likely to receive prenatal care, compared to older women, often seeking it only in the third trimester, if at all $[11,13]$. This was attributed to a number of reasons like lack of monetary resources to acquire necessities as required by the HWs.

\section{Interpersonal experiences of seeking ANC and delivery}

Many of the girls affirmed to receiving support from the people they stayed with or those who were around them. However, one of the respondents also claimed not to have received any kind of support from the people she stayed with. Most of what happened was due to a decision taken by her. Only a few of the girls in this study however made personal decisions to come for the services at the facilities. As far as decision making is concerned, the findings from the study indicate that most of the decisions were always made by the people these girls stayed with. These included their parents and spouses. These results are in agreement with the findings of a study that was carried out in Lesotho which showed that support during pregnancy had been associated with positive outcomes [7]. This further coincides with findings from a study in Bangladesh where most decisions were made by the parents or spouses to the girls since the men were usually the heads of the family and therefore took most household decisions while the mothers-in-law made decisions on healthcare [15].

\section{Health facility related experiences}

Many of the girls claimed to feel comfortable when they came to the health facility. For all the girls, on interaction, said that the HWs treated them well. They said that the HWs were always calm in the way they talked to them. The HWs were at times patient with them and showed kindness. This coincides with findings of a study carried out in Malawi where most of the girls felt they were cared for by the HWs [16]. The girls in this study continued and said, even in instances when they failed to do what was expected of them, the HWs were a little hard with them but later attended to them. This is unlike other studies carried out in other countries. In Bangladesh for example, findings suggest that quality of healthcare services and the attitudes of the health personnel was mentioned as a barrier to using maternal healthcare and less attention by the healthcare workers [15]. Some of the girls acknowledged receiving some education when they came for ANC. This coincides with a study carried out by Chikalipo in Blantyre, Malawi [16]. However, while some claimed the education was adequate, others felt there was some more that they needed to know. On the contrary, there are some of the girls who said they had not received any kind of education for the times they had visited the health facility. Similar findings were found in studies carried 
out in Ghana, Australia and India where the teenage girls had unmet need for information delivered at health facilities [17-19].

Some girls noted that the utilities were adequate, some found out that they were not adequate and therefore needed to be added. These included the beds, equipment used for checking them, the medicines and the limited number of HWs as well. Similar findings were noted in a study by Atuyambe in Wakiso, Uganda [14]. Many of the girls also said that the health facilities were accessible and felt the HWs in most cases worked on time save for a few of them who once in a while delayed. However, one outstanding challenge that most girls kept identifying was that the clients were in most cases many and at times with only one HW attending to them. Thus, in most cases delayed due to the large numbers. This coincides with findings from studies carried out in Ghana and Lesotho [20,7]. They did not also have any stigma apart from a few who were coming for the first time but were later able to get over it.

As such, most girls preferred using the health facilities as compared to the TBAs. This is because most of them said that at the health facility, one easily got assistance. This is unlike a study carried out in Bangladesh where adolescent girls relied on past events that other women gave birth at home without any problem. They therefore felt comfortable giving birth at home [15]. One of the girls in this study also said that HWs are better confidantes than TBAs. Whenever a TBA attended to a teenager, she would after go out and talk about her with other friends so she would rather continue seeking services from a health facility. This is contrary to a finding in Wakiso by Atuyambe where the girls identified the unprofessional nature of the HWs who shared the girls' secrets with their parents and other people [14]. However, few of the girls in this study said they would go to the TBA only to drink medicine, be palpated and depending on the nature of circumstances but would deliver from the health facility due to the nature of assistance offered.

\section{Strengths and limitations to the study}

\section{Strength}

The findings regarding experiences of seeking ANC and delivery among teenagers at health facilities in Kibuku District were obtained from the teenagers who had actually visited the facility which increased the reliability and validity of findings. In addition, the sampling of teenage mothers who participated in the indepth interviews was done in a number of health facilities that were randomly sampled. This increased transferability of the findings of this study.

\section{Limitations}

Most of the respondents were quite timid at the start of the interviews, they feared to respond to the questions and in most cases gave scanty information but the research team kept reassuring them of the confidential nature of the study and the findings gathered. This led to most of the respondents opening up. Some of the teenage girls had a recall bias. This was especially by those who had already given birth. 
As a necessity, constant probing was done to help them share their actual experiences and not what they think it should be or what they could have heard from their friends or other people.

\section{Conclusion}

The personal experiences of pregnant teenagers or those who had delivered at health facilities is that they knew the importance of seeking ANC and delivery at health facilities. Unfortunately, few of them sought these services from the health facilities and for those who did, this always came late. These were attributed to what they experienced as individuals like financial constraints limiting their ability to acquire necessities required by HWs, personal choice to give the baby time to develop and absence of their husbands to accompany them for tests as required by HWs.

Interpersonal experiences also played a significant role in their ANC seeking and choice to deliver at a HF. This included the people they stayed with: their husbands, parents, grandparents and friends. These played roles like offering support to the girls in form of buying the necessities, accompanying them to the health facilities as well as educating them on the importance of seeking ANC and delivering from a health facility. As a result, for most of these girls, the decision to seek services was made by these people they stayed with apart from a few who made their personal decisions.

The experiences with the health facilities also contributed to the seeking behavior of the teenage girls. For example, the comfort received by the girls at the facility, medication administered, the way they were treated by the HWs and the availability of utilities. In the course of interaction with the girls, some were able to elucidate how they managed to cope with some of the challenges they encountered while some suggested recommendations to avert some of the challenges they experienced.

Arising from this study, the research team recommends that: The teenage girls need to be sensitized by the health and social workers about the sensitive nature of their health when they are pregnant so that they are able to make personal decisions that will enable them seek the necessary services and on time. As per the findings, despite many of them having knowledge on the importance of seeking services at the health facilities, most of them initiated the visits late which could put their lives at risk. In addition, they need to be empowered and trained on skills that can enable them earn a living and sustain themselves rather than wait for support from their spouses or families which might never come or if it does, it is late. In the same vein, the people with whom these girls stay: parents, spouses and grandparents need to be sensitized on their responsibilities and the need to encourage these teenage girls to seek services early. This could be done through parental and spousal engagements in community dialogues where parents and spouses are empowered with skills to support these teenagers when they are pregnant and educate them on the benefits of seeking ANC. Health Workers who attend to the teenage girls in ANC need to provide adequate health education. The girls need to be educated on ANC; what it means to be pregnant at their age and what it takes to get good outcomes in the end like their hygiene, how they ought to feed and to start early preparation for delivery. In addition, the HWs need to educate the girls how important the medication they receive is to their lives. To solve the issue of stock outs, health facility in-charges are 
urged to make use of the essential medicines and supplies redistribution systems in the district where they can lodge in their deficits and shortages like medicines, equipment and medical personnel to the District Health Officer so that timely transfers are made from facilities that have surplus or they are acquired from relevant sources. In addition, more HWs also need to be correspondingly enumerated to be able to handle the overwhelming numbers of clients at the facilities.

Experiences obtained from the teenage girls were specifically for those who sought healthcare like ANC or delivery. This limited our findings to only the health facilities yet those in the communities could also have their own experiences. It would therefore add more value if experiences of the teenagers in the communities are also studied. This could perhaps give a different perspective and as well enrich the experiences of seeking ANC and delivery among teenagers at health facilities.

\section{Abbreviations}

WHO

World Health Organization; ANC:Antenatal Care; TBA:Traditional Birth Attendant; HW(s):Health Worker(s); HF:Health Facility.

\section{Declarations}

\section{Acknowledgements}

We thank the District Health Officer Kibuku and different facility in-charges for the permission to use their health facilities and staff for their support throughout the study. We also thank all the teenagers who participated in the study.

\section{Funding}

The study was funded from the authors' meager personal resources.

\section{Availability of data and materials}

The datasets during and analyzed during the current study are available from the corresponding author on reasonable request.

\section{Author's contributions}

RN conceptualized the study, developed the tools, collected and analyzed the data, interpreted the results, drafted and revised the manuscript. JNM and RKB: conceptualized the study, developed the tool, analyzed the data, interpreted the results, drafted and revised the manuscript. All the authors read and approved the final manuscript.

\section{Authors' information}


Ms. Rebecca Namusana is a student at Department of Maternal and Child Health, School of MedicineUganda Christian University, Mukono. Ms. Josephine Namyalo Mawerere lectures in Department of Maternal and Child Health, School of Medicine-Uganda Christian University Mukono. Prof. Robert K. Basaza lectures at the Department of Maternal and Child Health, Uganda Christian University Mukono and is the Director of Health Services at Gudie Incubation Centre, Kira Municipality Uganda.

\section{Ethical approval and consent to participate}

Ethical clearance was sought and granted by Uganda Christian University Ethical Review Committee, with approval number, 1311-600-0228. Informed consent to participate in the study was obtained from study participants.

\section{Consent for publication}

Written informed consent for the publication was obtained from the participants.

\section{Competing interests}

The authors declare that they have no competing interests.

\section{References}

1. UNICEF (2008) Young people and family planning: Teenage pregnancy. UNICEF Malaysia Communications.

2. World Health Organization (2020). WHO fact sheet on adolescent pregnancy. https://www.who.int.

3. Loaiza E, Liang M (2013). Adolescent pregnancy: A review of the evidence. New York: UNFPA.

4. Ahmed FR (2014). Highest teen pregnancy rates worldwide. World atlas.

5. UBOS and ICF (2016) Uganda demographic and health survey. Key indicators report (PR80).

6. Youth Equality Centre (2012). Initiating Self sustaining reproductive health program for youth people in Kibuku District.

7. SH Phafoli, EJ Van Aswegen \& UU Alberts (Part-time lecturer) (2007). Variables Influencing delay in the Antenatal Clinic Attendance among Teenagers in Lesotho. Journal of Advanced Nursing; Vol 49:9; p 17. https://doi.org/10.1080/20786204.2007.10873633.

8. DHIS 2 (2017). Uganda country summary: Maternal and Child survival program. https://www.mcsprogram.org.

9. Manzi F, Ogwang J, Akankwatsa A, Wokali OC, Obba F, et al. (2018) Factors Associated with Teenage Pregnancy and its Effects in Kibuku Town Council, Kibuku District, Eastern Uganda: A Cross Sectional Study. Prim Health Care 8: 298. doi: 10.4172/2167-1079.1000298.

10. Uganda Bureau of Statistics (2017). The National Population and Housing Census 2014 - Area Specific Profile Series, Kampala, Uganda. 
11. World Health Organisation. WHO recommendations on antenatal Care for a Positive. Pregnancy Experience. Geneva: WHO; 2016.

12. Atekyereza P and Mubiru K, (2014). Influence of Pregnancy perceptions on patterns of seeking antenatal care among women in reproductive age of Masaka district, Uganda. Tanzania Journal of Health Research. http://dx.doi.org/10.4314/thrb.v16i2.8.

13. Dairo M, Owoyokun K. Factors affecting the utilization of antenatal care services in Ibadan, Nigeria. Benin Journal of Postgraduate Medicine. 2010;12 (1). https://www.ajol.info/index.php/bjpm/article/view/63387. Accessed 6 July 2018.

14. Atuyambe L, Mirembe F, Tumwesigye NM, Annika J, Kirumira EK, Faxelid E (2008). Adolescent and Adult First Time Mothers' Health Seeking Practice during Pregnancy and Early Motherhood in Wakiso district, central Uganda, Reproductive Health Journal; Vol 5:4; pp 304-309. Available at http://www.reproductive-health-journal.com/content/5/1/13 (accessed 10/7/2015).

15. Shahabuddin A, Nostlinger C, Delvaux Therese, Sarker Malabika, Delamou Alexander, Bardaji Azucena, Jacqueline E.W Broerse, Vincent De Brouwere (2017). Exploring Maternal Health CareSeeking Behavior of Married Adolescent Girls in Bangladesh: A Social-Ecological Approach. PLoS ONE 12(1): e0169109.doi:10.1371/journal.pone.016910.

16. Maria Chifuniro Chikalipo, Linda Nyondo-Mipando, Rabecca Chikondi Ngalande, Sadandaula Rose Muheriwa, Usurla Kalimembe Kafulafula, 2018. Perceptions of pregnant adolescents on the antenatal care received at Ndirande Health Centre in Blantyre, Malawi.Malawi Medical Journal 30 (1): 25-30 March 2018. https://dx.doi.org/10.4314/mmj.v30i1.6.

17. Owusu-Addo SB, Owusu-Addo E, Morhe Es. Health information-seeking behaviours among pregnant teenagers in Ejisu-Juaben Municipality, Ghana. Midwifery.2016;41:110-117. doi:10.1016/j. midw.2016.08.007.

18. Grimes, HA., Forster DA., Newton, MS. Sources of information used by women during pregnancy to meet their information needs. Midwifery. 2014;30(1): e26-e33. doi:10.1016/jmidw.2013.10.007.

19. Das, A., Sarkar, M., 2014. Pregnancy-related health information-seeking behaviors among rural pregnant women in India: validating the Wilson Model in the Indian context. Yale Journal of Biology and Medicine 87, 251-262.

20. Bwalya C. Bwalya, Doreen Sitali, Kumar Sridutt Baboo and Joseph M.

Zulu, 2018. Experiences of antenatal care among pregnant adolescents at Kanyama and Matero clinics in Lusaka district, Zambia. Reproductive Health (2018) 15:124. https://doi.org/10.1186/s12978-018-0565-9.

\section{Supplementary Files}

This is a list of supplementary files associated with this preprint. Click to download.

- Suppl.docx

- Interviewguide.docx 
Page 24/24 